\title{
Determinant factors affecting the trends of permanent sterilization: a decadal analysis in a tertiary care institute
}

\author{
Meenakshi K. Bharadwaj ${ }^{1 *}$, Seema Patrikar ${ }^{2}$, Sanjay Singh $^{1}$
}

\begin{abstract}
${ }^{1}$ Department of Obstetrics and Gynecology, ${ }^{2}$ Department of Community Medicine, Armed Forces Medical College, Pune, Maharashtra, India
\end{abstract}

Received: 27 August 2017

Accepted: 25 September 2017

\section{*Correspondence:}

Dr. Meenakshi K. Bharadwaj,

E-mail: mkb.doc@gmail.com

Copyright: (C) the author(s), publisher and licensee Medip Academy. This is an open-access article distributed under the terms of the Creative Commons Attribution Non-Commercial License, which permits unrestricted non-commercial use, distribution, and reproduction in any medium, provided the original work is properly cited.

\begin{abstract}
Background: Permanent sterilization is a preferred method of contraception worldwide. In spite of popularization of temporary methods, it is used by $2 / 3^{\text {rd }}$ of married women using any contraception. It has a low incidence of complications and failure rate and is cost-effective. Various socio-demographic factors play a role in acceptability of this method. It has an important role in controlling the total fertility rate.

Methods: A retrospective record based analysis was done in armed forces personnel undergoing permanent sterilization operation over 11 years between 2005-2015 in a tertiary care institute. Analysis of trends in method choices of surgery, and comparison of the variables determining these choices was done. Year wise total fertility rates was calculated and the trend over 11 years was analyzed.

Results: Permanent sterilization operations were performed in 2121 couples over the 11 years period. Of total operations, $1823(85.95 \%$ with $95 \%$ confidence interval $=84.42,87.38)$ were done in females and $298(14.05 \%$ with $95 \%$ confidence interval $=12.62,15.58)$ in males. Female sterilization acceptance ranged between $71.6 \%$ to $91.6 \%$ and male sterilization between $8.4 \%-28.4 \%$ with an increasing trend towards male sterilization acceptance over the years. Total fertility rate declined from 2.3 to 2.09 in 11 years.

Conclusions: Increase in literacy rate of both the partners can positively impact the male involvement in permanent sterilization and control of TFR. This would help to stabilize India's population growth. Also, a decline in son preference can be beneficial for decline in fertility rate.
\end{abstract}

Keywords: Contraception, Family planning, Family size at sterilization, Family welfare programmes, Sterilization operation

\section{INTRODUCTION}

India is the first country in the world which officially adopted the family planning programme in 1952. This was launched to promote responsible and planned parenthood through voluntary family planning method. Couples have a choice of adopting temporary or permanent methods. There is a strong preference for permanent sterilization inspite of the efforts of popularization of temporary methods. Permanent sterilization, a one-step method, offers the longest continuation rate and lower failure rate. It is the most popular method for couples who have completed their family and want to limit their family size. National Family Health Survey (NFHS-3) data reveals a prevalence of permanent sterilization in $2 / 3^{\text {rd }}$ of married women who have used any contraceptive method and $77 \%$ of these women never used any other method before they underwent sterilization operation. ${ }^{1}$ Also, this is a preferred method in $63.9 \%$ of non-user married women. 
The methods of permanent sterilization include bilateral tubal ligation and vasectomy. Bilateral tubal ligation was first performed in 1823 to prevent pregnancy in women who needed repeat caesarean sections. ${ }^{2}$ This surgery has evolved over the years and can now be performed with caesarean section, immediately after a vaginal delivery or as interval tubal ligation. Complication rate with sterilization operations are rare but if they occur, they tend to be more serious with female sterilization because the procedure is more invasive. However, there is no significant difference between these two surgeries in the efficacy rate. ${ }^{3}$ There has been continued efforts by the government to popularize spacing methods. However, permanent sterilization remains the mainstay of national programme with female sterilization occupying the main bulk of it. According to the NFHS-3 and NFHS-4 data, of the total permanent sterilization operations $97.4 \%$ and $99.17 \%$ were female sterilization operations, respectively. This indicates that men's engagement is minimal in this process and has been declining over the years. ${ }^{3,4}$ Female sterilization is also the most widely used contraceptive method in the world. ${ }^{5}$

This study was done to assess the factors affecting the acceptability of two main categories of permanent sterilization and the trend of fertility in a sample representing Indian population.

\section{METHODS}

This is a retrospective register based study in which record based analysis considered the total armed forces personnel undergoing permanent sterilization operation during the last 11 years between 2005-2015 in a tertiary care institute. The focus was to enable analysis to capture recent trends in method choices of surgery, and comparison of the variables determining these choices. The dependent variable is the permanent sterilization methods which were classified into two categories: female sterilization and male sterilization. Female sterilization included tubectomy done laparoscopically, by minilaparotomy or with caesarian. Male sterilization included vasectomy by conventional or non-scalpel method.

The analysis included range of demographic characteristics like age, number and sex, composition of children. Cultural and socioeconomic characteristics like religion and education were also studied.

The data was extracted from the registers maintained in the Department of Obstetrics and Gynecology in the excel sheet. The qualitative variables were described using percentages and quantitative variables by mean and standard deviation. Year wise total fertility rates was calculated. The association of various variables with the type of surgery was carried out using chi square test. The trend over the 11 years was analysed using scatter plot and $\mathrm{p}$ value of 0.05 was considered for significance.
Ethical clearance was taken from the ethics committee of the institute.

\section{RESULTS}

Data of 2121 couples were extracted from the registers over 11 years of period. Of the total personnel 158 (7.4\%) were of high socio-economic status whereas remaining $1963(92.6 \%)$ personnel were from middle and low class.

The mean age of wife was found to be 28.94 years (SD 4.1) and husband to be 33.74 years (SD 4.5) for the female sterilization operation. This was 30.96 years (SD 4.9) and 35.40 years (SD 5.4) for wife and husband in cases of male sterilization, respectively. Majority of the people were Hindus making $94.7 \%$ of the operated couples with only $3.3 \%$ Muslims, $1 \%$ Christians and $0.8 \%$ Sikhs. Acceptance of male sterilization was maximum in Sikh couples $(72.2 \%)$ and minimum in Muslim couples (7\%). The socio demographic details are given in Table 1.

Table 1: Socio-demographic distribution of the personnel.

\begin{tabular}{|c|c|c|c|}
\hline Variables & $\begin{array}{l}\text { Female } \\
\text { sterilization, } \\
\text { n (\%) }\end{array}$ & $\begin{array}{l}\text { Male } \\
\text { sterilization } \\
(\%)\end{array}$ & $\begin{array}{l}\text { Total N } \\
(\%)\end{array}$ \\
\hline \multicolumn{4}{|c|}{ Age at sterilization } \\
\hline $\begin{array}{l}\text { Male (mean, } \\
\text { SD) }\end{array}$ & $33.74(4.498)$ & $35.39(5.44)$ & $\begin{array}{l}34.00 \\
(4.698)\end{array}$ \\
\hline $\begin{array}{l}\text { Female } \\
\text { (mean, SD) }\end{array}$ & $28.94(4.10)$ & $30.96(4.86)$ & $\begin{array}{l}29.229 \\
(4.276)\end{array}$ \\
\hline \multicolumn{4}{|c|}{ Socio-economic status } \\
\hline High & $125(79.1)$ & $33(20.9)$ & $158(100)$ \\
\hline $\begin{array}{l}\text { Middle and } \\
\text { low }\end{array}$ & $1698(86.5)$ & $265(13.5)$ & $\begin{array}{l}1963 \\
(100)\end{array}$ \\
\hline \multicolumn{4}{|l|}{ Religion } \\
\hline Hindu & $1732(86.2)$ & $277(13.8)$ & $2009(100)$ \\
\hline Muslim & $66(99)$ & $5(7)$ & $71(100)$ \\
\hline Christian & $19(86.4)$ & $3(13.6)$ & $22(100)$ \\
\hline Sikhs & $5(27.8)$ & $13(72.2)$ & $18(100)$ \\
\hline Others & $1(100)$ & $0(0.0)$ & $1(100)$ \\
\hline \multicolumn{4}{|l|}{ Education } \\
\hline \multicolumn{4}{|l|}{ Wife } \\
\hline No education & $274(15.03)$ & $45(15.1)$ & - \\
\hline $\begin{array}{l}<8 \text { years } \\
\text { complete }\end{array}$ & $188(10.3)$ & $28(9.4)$ & - \\
\hline $\begin{array}{l}9-12 \text { years } \\
\text { complete }\end{array}$ & $926(50.8)$ & $169(56.7)$ & - \\
\hline $\begin{array}{l}13 \text { years or } \\
\text { more complete }\end{array}$ & 435 (23.8) & $56(18.8)$ & - \\
\hline \multicolumn{4}{|l|}{ Husband } \\
\hline $\begin{array}{l}10-15 \text { years } \\
\text { complete }\end{array}$ & $1368(75.04)$ & $241(80.9)$ & - \\
\hline $\begin{array}{l}15 \text { years or } \\
\text { more complete }\end{array}$ & 457 (25.06) & $57(19.1)$ & - \\
\hline
\end{tabular}

Of these total sterilization operations, 1823 (85.95\% with $95 \%$ confidence interval $=84.42,87.38)$ were female sterilization operations and $298(14.05 \%$ with $95 \%$ 
confidence interval $=12.62,15.58)$ were male sterilization operations (Figure 1). Of the high socioeconomic status couples female sterilization was done in $79.1 \%$ and male sterilization in $20.1 \%$ whereas in middle and low status couples higher female sterilization operations were observed in $86.3 \%$.

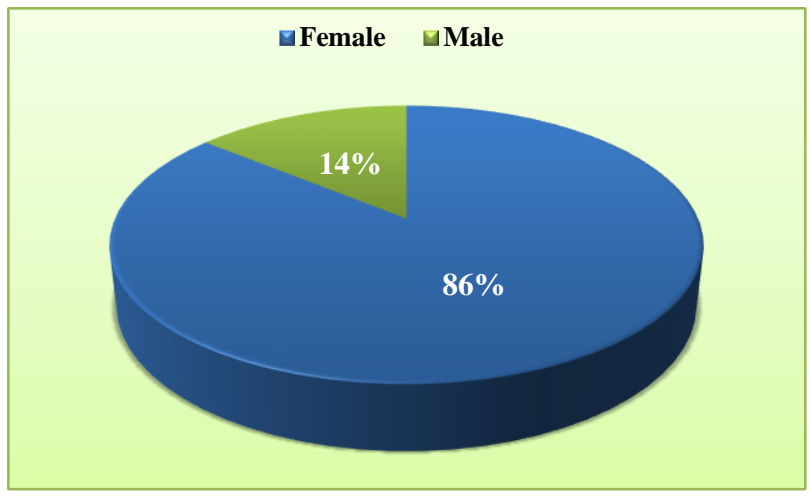

Figure 1: Distribution of respondents as per type of sterilization operation.

It was observed that $15 \%$ women undergoing female sterilization were illiterate. Same percentage of women whose spouses were undergoing male sterilization operation were uneducated.

All men were educated for a minimum of 10 years. Maximum number of women operated had completed 9 to 12 years of education.

The acceptance of sterilization operation was maximum after 2 children observed in $80.4 \%$ of couples. It was $2.1 \%$ after one child, $16 \%$ after three children, $1.6 \%$ after four or more children.

Interestingly, in $32.3 \%$ couples, sterilization operation was accepted without a male child and $44.3 \%$ and $23.4 \%$ accepted it after one male child and two or more male children, respectively (Table 2 ).

Table 2: Distribution with respect to number and sex of children.

\begin{tabular}{|c|c|c|c|}
\hline Variables & $\begin{array}{l}\text { Female } \\
\text { Sterilization } \\
\text { n }(\%)\end{array}$ & $\begin{array}{l}\text { Male } \\
\text { Sterilization } \\
\text { n (\%) }\end{array}$ & Total n (\%) \\
\hline \multicolumn{4}{|c|}{ No. of children } \\
\hline 0 & - & - & - \\
\hline 1 & $23(1.26)$ & $21(7.05)$ & $44(2.07)$ \\
\hline 2 & $1470(80.63)$ & $235(78.86)$ & $1705(80.39)$ \\
\hline 3 & $303(16.63)$ & $36(12.08)$ & $339(15.98)$ \\
\hline 4 or more & $27(1.48)$ & $6(2.01)$ & $33(1.56)$ \\
\hline \multicolumn{4}{|c|}{ Male children } \\
\hline 0 & $650(35.7)$ & $36(12.1)$ & $686(32.3)$ \\
\hline 1 & $771(42.3)$ & $168(56.4)$ & $939(44.3)$ \\
\hline 2 & $382(21)$ & $90.0(30.2)$ & $472(22.3)$ \\
\hline 3 or more & $20(1.1)$ & $4(1.3)$ & $24(1.1)$ \\
\hline
\end{tabular}

\section{Trend analysis}

The year wise distribution of the respondents with regard to type of sterilization operation from 2005 to 2015 is shown in Table 3 and Figure 2. It was observed that maximum percentage of female sterilization operations were performed in the year 2008 and minimum in the year 2014 with a range of $71.6 \%$ to $91.6 \%$. The male sterilization operations of the total sterilization operations done in each year ranged between $8.4 \%-28.4 \%$. The data showed significant declining trend in acceptance of female sterilization and increasing trend in male sterilization $(\mathrm{p}=0.000)$.

Table 3: Distribution of couples as per type of sterilization operation.

\begin{tabular}{|llll|}
\hline Year & $\begin{array}{l}\text { Female } \\
\text { sterilivation } \\
\text { n }(\%)\end{array}$ & $\begin{array}{l}\text { Male } \\
\text { sterilivation } \\
\text { n }(\%)\end{array}$ & $\begin{array}{l}\text { Permanent } \\
\text { sterilization } \\
\text { n }(\%)\end{array}$ \\
\hline 2005 & $181(81.2)$ & $42(18.8)$ & $223(100)$ \\
\hline 2006 & $156(84.3)$ & $29(15.7)$ & $185(100)$ \\
\hline 2007 & $210(89.4)$ & $25(10.6)$ & $235(100)$ \\
\hline 2008 & $228(91.6)$ & $21(8.4)$ & $249(100)$ \\
\hline 2009 & $233(90.0)$ & $26(10.0)$ & $259(100)$ \\
\hline 2010 & $208(91.2)$ & $20(8.8)$ & $228(100)$ \\
\hline 2011 & $171(84.2)$ & $32(15.8)$ & $203(100)$ \\
\hline 2012 & $138(86.3)$ & $22(13.8)$ & $160(100)$ \\
\hline 2013 & $94(81.7)$ & $21(18.3)$ & $115(100)$ \\
\hline 2014 & $96(71.6)$ & $38(28.4)$ & $134(100)$ \\
\hline 2015 & $108(83.0)$ & $22(16.9)$ & $130(100)$ \\
\hline Total & $1823(86)$ & $298(14)$ & $2121(100)$ \\
\hline
\end{tabular}

The data revealed a decline in the total fertility rate measured as average number of children that are born to a woman if she experiences the current fertility pattern throughout her reproductive span (15-49 years).

Comparison with national figures for India between 2005 and 2015 is shown in Table 4 . Total fertility rate ranged between 2.09 to 2.3 in the present study population. It was maximum in the year 2005 and gradually declined to the minimum of 2.09 in the year 2014 .

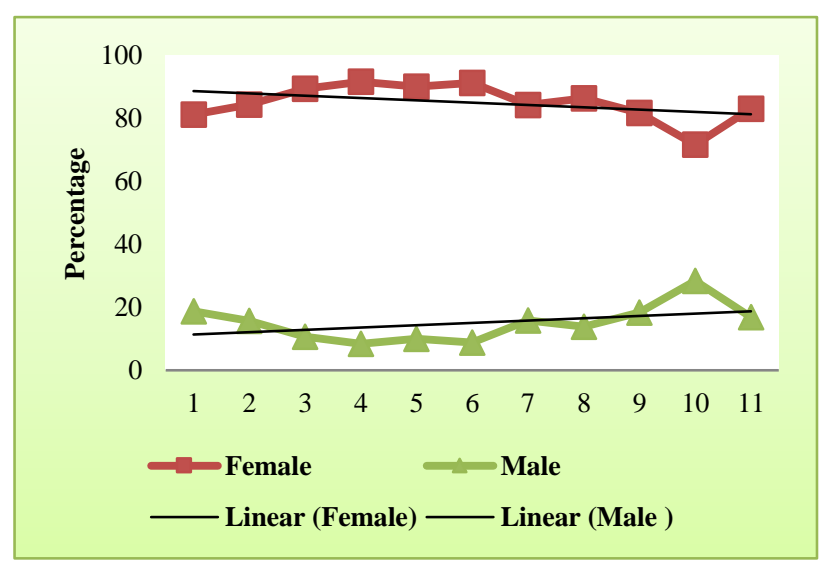

Figure 2: Percentage distribution of respondents as per type of sterilization operation. 


\section{DISCUSSION}

The socio-demographic characteristics reveal a key relation with the permanent sterilization acceptance. Mean age of woman undergoing female sterilization operation in the current study was 28.9 years which was comparable to mean age 27.5 years found in a study carried out amongst rural population of Gujarat. ${ }^{6}$ This figure was 25.5 years according to NFHS-3 data indicating an early acceptance of female sterilization by the couples in India. Mean age at which men underwent sterilization was 35.40 years with mean age of their spouse at 30.96 years in the study. This was also higher than that of NHFS-3 data of mean age of men being 30.6 years and their spouse 25.3 years, respectively. Murthy and Rao in a study done in a state where the fertility rate is low found the mean age of vasectomy acceptors as 32 years and that of spouses as around 26 years. ${ }^{7}$

Similar to the NFHS-3 data, the current study also revealed that the majority of women who underwent female sterilization were Hindus. In this study there was a strong association of preference of male sterilization in Sikh couples however due to a very small number of Sikh study population as compared to the total it cannot be statistically correlated with the rest of the religions. NHFS-3 data revealed that Muslim women tend to prefer temporary methods rather than sterilization, strongly associated with the comparatively low prevalence of sterilization operations in this community. In other religions the preference for permanent sterilization by type is comparable to the Hindus.

Improving the literacy rate can be beneficial in controlling the population growth of the country. In the present study, revealing a declining trend in total fertility rate, there were $85 \%$ literate women and complete literacy rate amongst men. Two studies done in two different rural areas of India revealed higher illiteracy rate of $45 \%$ and $23 \%$ amongst the women undergoing female sterilization. ${ }^{8-10}$ The total fertility rate was also higher at 2.84 and 2.36 in these studies, respectively. Increase in literacy rate has a higher proportion of men and women accepting modern contraceptive method, permanent sterilization being one of them, due to a reported exposure to family planning messages through various channel of communication. ${ }^{1}$ The high use of permanent sterilization in the southern states with better education incidence has been correlated with high demand for lower family size and better network of family planning services. ${ }^{10}$ Education is found to have positive role in increasing the acceptance of modern contraceptive method world over. ${ }^{11-13}$

The number and sex of the child is a key determinant factor in acceptance of permanent sterilization. Desire for male child is hurdle in acceptance of sterilization operation but this is not consistent with the present study due to positive effect of high literacy rate of the study population. ${ }^{14}$ The acceptance of sterilization operation was maximum after 2 children seen in $80.4 \%$ of couple and $32.3 \%$ of couples accepted it without a male child. Pandit NB and Patel TA reported that $45.8 \%$ of women had three or more children and $98.8 \%$ women had at least one male child before they accepted female sterilization. ${ }^{6}$ Puwar et al similarly observed that $39 \%$ of the study subjects had at least three children and $98.9 \%$ had at least one male child in the family before they accepted sterilization. $^{8}$ NFHS-3 found a positive relationship between couples opting for sterilization operation and number of living children. This study has revealed information related to trends in permanent sterilization acceptability in between 2005-2015. There was no significant change in the percentage of permanent sterilization operation over the years and the female sterilization has been the predominant method of sterilization operation amongst the two types ranging between $71.6 \%$ to $91.7 \%$ with the trend of increased acceptance of male sterilization. NFHS-3 and NFHS-4 data also reveals a significant preponderance towards female sterilization operations with $97.4 \%$ and $99.17 \%$ female sterilization operations, respectively. ${ }^{1,4}$ Over the years acceptance pattern seems to be significantly biased towards female sterilization. However, in the study the acceptance towards male sterilization is more than the national average for our country. This trend could be due to improvement in the literacy rates of the target population. Counselling of the couples as a variable leading to this improvement could not be analysed further as this was a retrospective study and data related to counselling was not available in the sterilization registers. It may be deduced from the TFR in the present study that promotion of vasectomy use could be beneficial for reducing the overall family size. Male sterilization also has a number of advantages over female sterilization. The surgery is less extensive, has similar efficacy and lesser side effects. ${ }^{3}$ Since male reproduction capacity continues for a longer age as compared to females, male sterilization can offers contraceptive benefit for a longer duration. ${ }^{15}$

\section{Table 4: Total fertility rate in the current study and} national figures.

\begin{tabular}{|lll|}
\hline Year & Current study & National figures \\
\hline 2005 & 2.30 & 2.9 \\
\hline 2006 & 2.22 & 2.8 \\
\hline 2007 & 2.14 & 2.7 \\
\hline 2008 & 2.20 & 2.6 \\
\hline 2009 & 2.10 & 2.6 \\
\hline 2010 & 2.18 & 2.5 \\
\hline 2011 & 2.22 & 2.4 \\
\hline 2012 & 2.12 & 2.4 \\
\hline 2013 & 2.14 & 2.3 \\
\hline 2014 & 2.09 & 2.3 \\
\hline 2015 & 2.10 & 2.3 \\
\hline
\end{tabular}

Also, this study has shown that the trend of the average number of living children at the time of contraception declined from 2.3 to 2.09 . The total fertility rate is lower 
compared to the national average although it has also been declining over the years from 2.9 in 2005 to 2.3 in 2015 (Table 4). ${ }^{16}$

Many other studies have revealed a similar declining trend over the years. ${ }^{17-19}$ Decrease in the TFR is one of the main targets of national family planning programmes. It is an important determining factor for stabilization of population of the country. Another indirect benefit of decrease in TFR is reduction in the maternal mortality ratio because it reduces the number of times the lady becomes pregnant and the risks associated with it. ${ }^{20}$ It has been observed that there is a preference for male child which is one of the factors responsible for repeated number of pregnancies. The sex ratio of India has been declining over the years with an increase in male children. Unfortunately, the girl child is not the preferred child and although couples desire smaller families, they want to have a male child. ${ }^{21} \mathrm{We}$ have not been able to use NHFS-4 data for detailed comparison within the study due to its non-availability.

\section{CONCLUSION}

It can be concluded from this study that increase in acceptance of male sterilization can positively impact the control of TFR. Indian population of 1.21 billion as on $21^{\text {st }}$ March 2011 comprising $17.5 \%$ of world population is likely to increase to 1400 million in 2026. Control of TFR would help to stabilize India's population growth which in turn can spur the economic and social progress of the country. As male involvement in family planning remains negligible in India, men taking initiative to undergo sterilization operation and not shying away from this responsibility can improve their contribution in control of the family size. Another major outcome revealed over 10 years of the study is that improvement in the literacy rates of the target population can increase in the acceptance of male sterilization.

It is important to focus efforts and resources to formulate and implement integrated programmes for reducing gender bias in permanent sterilization that can effectively and efficiently increase the acceptability of male sterilization in the country. Improving the overall literacy rate and developing policies to provide comprehensive reproductive health education related to decline in sexratio due to son preference as part of school curriculum can discourage couples preference of male child.

\section{ACKNOWLEDGMENTS}

The author is grateful to the staff of Department of Obstetrics and Gynecology, Armed Forces Medical College, Pune, and the patients on whom the operations were performed.

Funding: No funding sources Conflict of interest: None declared
Ethical approval: The study was approved by the Institutional Ethics Committee

\section{REFERENCES}

1. International Institute for Population Sciences (IIPS) and Macro International. National Family Health Survey (NFHS-3), 2005-06: India: Volume I. Mumbai: IIPS. 2007.

2. Decherny $H$, Nathan L, Goodwin $T$, Laufer $N$. Diagnosis and Treatment Obstetrics and Gynecology. $10^{\text {th }}$ ed. New York: McGraw Hill; 2003;48:804.

3. Smith GL, Taylor GP, Smith KF. Comparative risks and costs of male and female sterilization. Am $\mathbf{J}$ Public Health. 1985;75(4):370-4.

4. National Family Health Survey (NFHS-4), 2015-16: India Fact Sheet. Ministry of Health and Family Welfare. Available at http://rchiips.org/NFHS/pdf/NFHS4/India.pdf

5. UN 2009 United Nations, Department of Economic and Social Affairs, Population Division. World Contraceptive Use 2009. Available at http://www.un.org/esa/population/publications/WCU 2009/Main.html

6. Pandit NB, Patel TA. A descriptive study on determinant factors of who accepted sterilization in rural Vadodara. Nat $\mathrm{J}$ Community Med. 2013;4(3):424-7.

7. Murthy SR, Rao MD. An analysis of Factors influencing the Acceptability of Vasectomy in Andhra Pradesh. Health and Population Perspectives and Issues. 2003;26(4):162-82.

8. Puwar B, Patel V, Patel M. Factors affecting sterilization operation among couples of a rural area in Ahmedabad: A record-based study. Indian J Med Sci. 2012;66:267-72.

9. Athavale AV, Athavale SA. Factors influencing the decision to undergo tubectomy in rural Area of Maharashtra. Regional health: forum WHO South East Asia Region. 2003;7:42-7.

10. Singh A, Pallikadavath S, Ram F, Ogollah R. Inequalities in advice provided by public health workers to women during antenatal sessions in rural India. PloS One. 2012;7(9):e44931.

11. Jejeebhoy SJ. Women's education, autonomy, and reproductive behaviour: Experience from developing countries. OUP Catalogue. 1995.

12. Moursund A, Kravdal O. Individual and community effects of women's education and autonomy on contraceptive use in India. Population Studies. 2003;57(3):285-301.

13. Cates W Jr, Maggwa B. Family planning since ICPD how far have we progressed?. Contraception. 2014;90(6):S14-S21.

14. Oliveira ITD, Dias JG, Padmadas SS. Dominance of sterilization and alternative choices of contraception in India: an appraisal of the socioeconomic impact. PloS One. 2014;9(1):e86654.

15. Bartz D, Greenberg JA. Sterilization in the United States. Rev Obstet Gynecol. 2008;1(1):23-32. 
16. Health and family welfare statistics of India 2015 . Available at www.nrhmmis.nic.in/PubFW_Statistics2015

17. Saha SP. Trend of socio-demographic characteristics of tubectomy acceptors in a rural area of West Bengal (Singur). Indian J Public Health. 1981;25:102-10.

18. Mehta DC, Shah MH, Khatri TD. Demographic characteristics of tubectomy acceptors in Kaira district. J Fam Welfare. 1975;22:32-40.

19. Mumbare SS, Gosavi S, Almale B, Patil A, Dhakane $\mathrm{S}, \mathrm{Kadu} \mathrm{A}$. Trends in average living children at the time of terminal contraception: a time series analysis over 27 years using ARIMA (p, d, q) non-seasonal Model. Ind J Community Med. 2014;39(4):223-8.
20. Wilmoth J. The lifetime risk of maternal mortality: concept and measurement. Bulletin of the World Health Organization. 2009;87(4):256-62.

21. Ministry of Health and Family Welfare, Office of the Registrar General and Census Commissioner, India United Nations Population Fund (UNFPA). Missing. Mapping the adverse child sex ratio in India. New Delhi: Ministry of Health \& Family Welfare; 2003. Available at https://www.popline.org/node/563003.

Cite this article as: Bharadwaj MK, Patrikar S, Singh S. Determinant factors affecting the trends of permanent sterilization: a decadal analysis in a tertiary care institute. Int J Reprod Contracept Obstet Gynecol 2017;6:5348-53. 